\title{
The Belgian DNA Debate: An Online Deliberative Platform on the Ethical, Legal, and Social Issues of Genomics
}

\author{
Chloé Mayeur Marlies Saelaert Wannes Van Hoof \\ Cancer Centre, Sciensano, Brussels, Belgium
}

\section{Keywords}

Genomics - Ethical, legal, and social issues - Governance .

Public participation - Online deliberative platform

\begin{abstract}
Introduction: Genomics is increasingly being implemented in the society. To fully realise this implementation, citizens should be consulted about their perspectives on genomics and its associated ethical, legal, and social issues (ELSI) to enable them to co-create with experts a society-supported framework in genomics. Methods: A Belgian online DNA debate was organised, where 1,127 citizens contributed to its deliberative platform. Results: Contributors expressed a dual attitude towards the societal use of genomic information throughout 5 main themes. Firstly, contributors considered DNA to have a significant but nondeterministic impact on identity. The second theme describes how genomic information may guide people's behaviour but has unfavourable effects such as psychological distress. The third theme covers the tension between a genomics-based responsibility and the rejection of genetic discrimination. The fourth theme depicts how genomic information may be useful for the common good and society at large but how, nevertheless, it should be people's free choice to use this information. In the fifth theme, contributors expressed both willing-
\end{abstract}

ness to share their data and caution towards the harm and abuses this may engender. Finally, contributors formulated some recommendations for the responsible implementation of genomics. Discussion and Conclusion: The attitude of contributors towards the societal use of genomic information and its ELSI aligns with a soft precautionary approach, in which prudence and the weighing of different values should result in protective measures against potential risks and harms. Further societal implementation of genomics should include these values and concerns.

(C) 2021 The Author(s)

Published by S. Karger AG, Basel

\section{Introduction}

Genomic information is used increasingly in medicine. Several countries have already made considerable investments to implement genomics in mainstream health care [1,2]. Genomics England sequenced 100,000 genomes of patients and their relatives and spent over 415 million US dollars to establish a centralised infrastructure for whole-genome sequencing services [2]. The French Plan for Genomic Medicine 2025 and Australian Genomics launched numerous projects to integrate genomics into health care and evaluate its clinical utility and costeffectiveness [2]. On a European level, the collaborative karger@karger.com www.karger.com/phg

Karger $\stackrel{\text { ' }}{5}$

GOPEN ACCESS
(C) 2021 The Author(s)

Published by S. Karger AG, Basel

This is an Open Access article licensed under the Creative Commons Attribution-NonCommercial-4.0 International License (CC BY-NC) (http://www.karger.com/Services/OpenAccessLicense), applicable to the online version of the article only. Usage and distribution for commercial purposes requires written permission.
Correspondence to:

Chloé Mayeur, chloe.mayeur@ sciensano.be 
1+ Million Genomes initiative has been launched to sequence at least 1 million genomes by 2022 to improve disease prevention and personalised treatments [3]. Besides healthcare services, genealogical and forensic services sometimes use genomic technologies. Consequently, everyone may likely be confronted directly or indirectly with genomics shortly [4-6].

What is more, the full accomplishment of genomics relies on the collection and sharing of data from patients and the general population $[4,7]$. The involvement and trust of citizens are required to build a representative dataset and sustainable database, which would facilitate an accurate interpretation of genetic variants and data $[2,8$, 9]. Additionally, the implementation of genomic technologies in national healthcare systems often implies a "learning-by-doing" approach [10], which ensures that routine diagnostics in clinical care are embedded in a larger evidence-generating framework. Evidence and knowledge of innovation are generated in real time, avoiding demanding, expensive, and time-consuming phase II and III clinical trials. However, this approach entails an interface between research and care, with careful ethical considerations [8].

For all the aforementioned reasons, it is important to include a citizen perspective on genomics and its associated ethical, legal, and social issues (ELSI) to ensure that societal values guide the technology and not the other way around. Global citizen deliberation has been recognised as an essential step when implementing genomic technologies [11]. Understanding the citizens' lay expertise and values may enrich the analysis of ELSI in genomics and be essential to install appropriate engagement and communication strategies $[4,12]$. In recent years, various international initiatives have been taken in which citizens, together with experts, actively engaged in the cocreation of an ethical framework concerning ELSI in genomics. Within the Genomics England project, citizens indicated that genomics should be organised as a form of a social contract with reciprocity, altruism, and solidarity as core values [13]. The Sienna project aims to capture European public views on the ELSI of human genetics and genomics, human enhancement, artificial intelligence, and robotics [12]. In France, the bioethical law review entailed public consultations with a specific interest in genomics [14]. In Belgium, a citizen forum was organised on request of the Ministry of Public Health [15]. The Belgian DNA debate attempts to apply these deliberative principles to an online methodology reaching a larger population.

\section{Methods}

The Belgian DNA debate was organised as an online deliberative platform to investigate Belgian citizens' attitudes towards genomics and its associated ELSI. Such intervention aims at creating a space where citizens can meaningfully contribute to producing policies or other forms of governance $[16,17]$. Online public deliberations tend to evoke well-sourced, factually argued, and more explicitly justified arguments [18]. Moreover, they tend to be oriented more manifestly to the common good, for instance, collective solutions that transcend personal interests; which may be relevant to topics such as the societal use of genomic information [18].

The open call to participate was disseminated in national media (newspaper articles, radio, and television interviews), newsletters from partnering organisations and high school teachers' groups on Facebook. Although this call was limited to Belgian information channels and the Website was only Dutch- and French-speaking, a few contributions may not be from Belgian citizens. However, all students who participated came from about 75 high schools in Belgium, and activity on the Website corresponds strongly to the timing in the Belgian communication strategy.

The online debate followed the general structure of a participative intervention around mini-publics: inform, deliberate, and produce $[16,17]$. The project deployed 4 strategies to inform citizens before participation: an information booklet, a short video, an interactive test, and a pedagogical dossier. These information materials contained practical cases, real-life examples, and discussion exercises to elicit deliberation about the ELSI in genomics and help teachers challenge their students in the classroom. All information materials and media publications contained links to the DNA debate Website.

A dedicated Website (dnadebat.be/debatadn.be) was launched in Dutch and French to gather citizens' contributions and stimulate further debate. This Website was designed for directing visitors to the deliberative platform, for example, through the interactive test indicating what kind of society they would live in if everyone had the same opinion as them about genomics. The debate was structured around 1 central question - How should we use genomic information in society? - followed by 5 sub-questions to provide participants with more structure:

1. What encourages me to learn more about my DNA, or what dissuades me from doing it? Why?

2. What motivates me to share my DNA data, or what stops me from doing so? Why?

3. A genetic passport for all: a good idea or not? Why?

4. How would DNA be used in my ideal society? What applications should be avoided? Why?

5. Do you want to share another idea about how we should deal with DNA in society?

To post their contributions, each participant had to create an anonymous account on the Website by choosing their alias. Since every account was linked to a unique IP address, Google Analytics guaranteed that each participant posted their contributions through the same account. However, the participants could post as many contributions as they wanted. Each contribution was moderated to eliminate offensive language and trolling, but moderation was limited to minimum to allow all opinions to be heard. In total, 4,545 citizens interacted with the Website between October 15, 2019 and March 20, 2020; 2,581 citizens filled in the interactive 
test; 1,127 citizens contributed to the deliberative platform, which ultimately contained 1,258 individual threads. Every thread represented 1 opinion shared by a contributor, followed by a comments section. In this article, we will focus on the content created on this deliberative platform.

Our goal was to identify the fundamental norms and values held by contributors regarding genomic information usage. All the contributions were treated as 1 big narrative to perform an inductive thematic analysis using NVivo 12 software [19]. In this qualitative method, the initial coding is not restricted to any predefined conceptual framework to let themes emerge from the data naturally. The questions from the Website were only used to understand the contributions in their proper context. Three researchers performed data analysis and regularly discussed interpretation and interconnectedness between the themes. Since contributions were both in French and Dutch, all researchers were fluent in both the languages.

\section{Results}

Contributors frequently had a dual attitude towards genomic information usage and balanced its potential benefits with its risks. On the one hand, many contributors believed in the responsible and valuable use of genomic information, for instance, for preventive medicine or scientific research. On the other hand, many contributors argued that not all the information contained in the genome should be known and not everyone should be able to use it for any purpose since this might engender various risks and harms.

Contributors' dual attitude on genomic information and its potential uses was expressed in 5 main themes: I. DNA and identity, II. genomic information and its impact on behaviour, III. genomic information and its repercussion on responsibility, IV. the common good, V. genomic data sharing and protection, and finally, VI. recommendations on using genomic information to summarise contributors' suggestions throughout the previous themes. Figure 1 presents the main results schematically.

\section{DNA and Identity}

On the one hand, contributors thought genomic information is by far the most personal information since it is unique to every person. Besides concerning an individual's physical constitution, character traits, and talents, it refers to someone's roots and relatives. Hence, genomic information was regarded sometimes as a blueprint of someone's past, current, and future identity. Contributors depicted how this blueprint does not only allow identifying somebody but also characterising and broadly understand this person.Over the short to medium term, I think DNA will allow understanding the intimate functioning of the human being; perhaps even how I manage my own emotions (Thread no. 71).

On the other hand, contributors made some nuances in the influence of genomics on personal identity since they understood that DNA is 1 influencing component among many others. Contributors suggested that their identity is also affected by education and practice, socioeconomic context, and the environment. Furthermore, they argued that genetic predispositions, especially for disease, only indicate chances and not absolute certainties, which further reduces the decisive influence of genomics on someone's life and identity.

Both perspectives were repeatedly united in the idea that despite the significant impact of DNA on identity, people should not be categorised purely based on their DNA but should be judged based on their actions too. This significant but non-deterministic impact of DNA was expressed in medical, professional, and recreational contexts.Requirements might be imposed concerning your DNA to obtain a particular professional position. Anywaqy, it's going to get lots of attention. However, your DNA is only an indication of your talents, and it doesn't cover everything (Thread no. 1104).

\section{Genomic Information and Its Impact on Behaviour}

Very frequently, contributors had a dual attitude towards the impact of genomic information on behaviour. A common reason for interest in genomic information was that this knowledge would allow for prevention or lifestyle changes and provide more control over life. Despite the potential benefits of these actions, contributors mentioned various unfavourable effects of genomic information. Firstly, they often warned that if the knowledge of genetic predispositions enables to avoid future disease, it can also cause psychological distress. This way, genomic information holds the paradox of potentially taking away future harms while simultaneously creating another type of harm, namely, worrying about a potential disease. The inherent uncertainty concerning most genetic predispositions also entails the risk of undue worries since these predispositions might never express themselves. In either case, many contributors feared that this psychological distress could undermine a general carelessness in life and prevent somebody from enjoying life to the fullest. Moreover, some contributors stated that genomic information and its resulting psychological concerns could paradoxically have a demotivating behavioural effect and inhibit preventive actions. To avoid these risks, many contributors expressed a selective inter- 


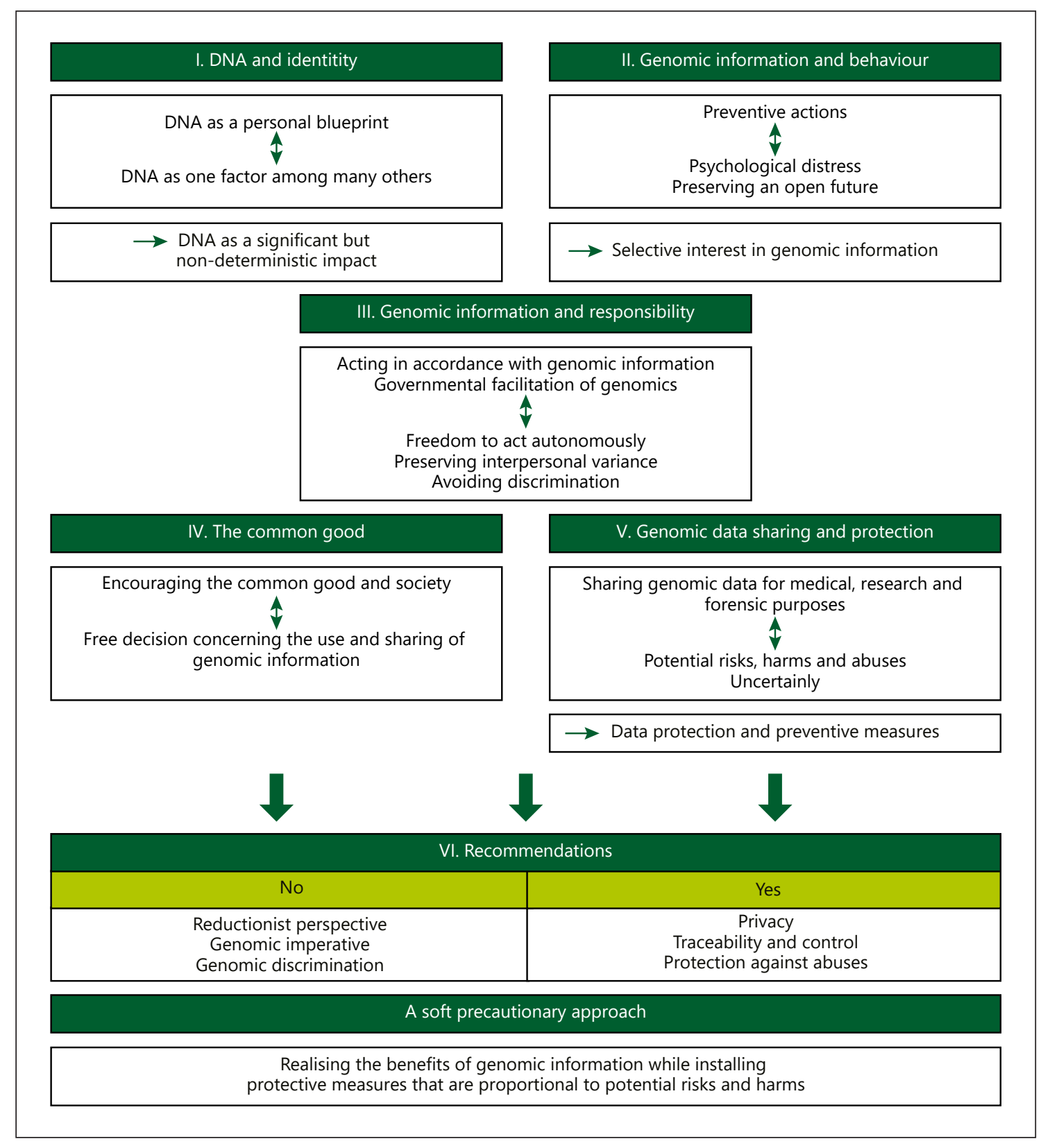

Fig. 1. Citizens' main attitudes and recommendations towards the societal use of genomic information.

est in genomic information in which, for instance, they did not want to know about predispositions to diseases to which no treatment or prevention is available.I would only like to know that I'm at high risk for severe illnesses when these can be prevented. If this is not the case, I would not want to know, because I would give up and I would not be able to make the most of life anymore. I think that DNA research should only be used when it can help people or save lives (Thread no. 1135).
Secondly, some contributors mentioned that knowing too much genomic information would make life overly predefined. Instead, they preferred a partly open future with room for the unexpected. One way to preserve this was, for example, to not enquire genomic information concerning personal characteristics or talents. Being in good health and preferring to solve problems the moment they arise additionally supported this selective interest in genomic information. 
Genomic Information and Its Repercussion on

Responsibility

Some contributors mentioned that genomic information could inherently introduce the responsibility to act accordingly. Examples cited referred to reproductive decisions (e.g., choosing for assisted reproduction to avoid an at-risk or ill child) or family communication (e.g., informing relatives about genetic predispositions). Several contributors said that they did not want genomic information to guide their life. In these cases, not knowing about genetic predispositions was considered an effective solution to avoid or temper the responsibilities that genomic information may imply.

However, different contributors argued that the responsibility engendered by genomic information should not be taken too far and should not equal the obligation to apply this information to associated actions, whether preventive, therapeutic, or behavioural. Genetic risks should, for instance, not deprive people of their right to find a family. Additionally and despite genetic predispositions and innate talents, people should be free to decide autonomously on their behaviour, profession, hobbies, and the like. This idea is in line with the preference of an (partly) open future. Moreover, people's freedom to act or not following their genomic information and their ability to accomplish things beyond their innate predispositions further supports the opinion that people should not be judged solely based on their DNA.I believe in the willpower of people and their ability to push their boundaries. DNA tells us a few things about us, but we still pull the strings. It is like a cookbook. Once you've read the recipe, you still have the choice whether or not to follow it. And even if you follow it, you are free to beat the book and do your own thing, to go beyond the example. We have that power, we determine what we (want to) achieve in life, and our DNA is just a tool (Thread no. 907).

Some contributors further reduced the responsibility to know or act following their genomic information by claiming that it is not up to humankind to decide on some issues. Examples are the health of future children or the desirable characteristics of people. This idea was associated with the belief that eliminating interpersonal variance could lead to the societal disapproval of individuals who do not meet particular standards.I think that people would make some decisions based on the results of DNA tests and, this way would eliminate all disabilities, for instance. It will be more common for people to abort a child with a disability. I think this is very destructive for society! Diversity is important; everyone is unique. In my opinion, it should stay that way (Thread no. 549).
In addition to these reflections on personal responsibility, many contributors referred to societal and governmental responsibilities regarding genomic information. Again, these ideas were 2-fold. Many contributors believed that the knowledge and use of genomic information should be supported and facilitated by the government. However, the increased availability and use of genomic information should not result in genetic discrimination: despite people's knowledge of genetic risks and even when people are unable or unwilling to act in accordance with their genomic information, the society and government should avoid that these people fall victim to professional, financial, or social discrimination.

\section{The Common Good}

The majority of contributors supported the knowledge and use of genomic information for at least medical, scientific, and forensic purposes. Many contributors would be willing to share their genomic data to facilitate these uses, provided that several protective conditions were met (cf. infra). Many contributors situated the value of genomic information, both in its use for individual interests and the encouragement of the common good and society. This way, issues at the individual's discretion were distinguished from those where the common good may, under certain conditions, determine the use of genomic information or even overrule personal benefit. Several contributors mentioned that if no one shares their genomic data, scientific progress and new medical treatments cannot be achieved. Other contributors suggested that people's DNA could be used for forensic research without their permission or that a genetic passport would be most effective if, without exception, everyone participated.I think (a genetic passport) is a good idea. The medical world will be able to discover new treatments for common diseases. It would allow treating some illnesses faster and more efficiently, which is advantageous for the patient and society. However, I think that some rules need to be established. Not everyone should have access to everyone's genetic passport. I think only medical people should have access because after all, they are the ones who can treat diseases (Thread no. 1236).

Nevertheless, most contributors agreed that as a general rule, citizens should not be forced to know, use, or share their genomic information. Supported by genomic information's profoundly personal character, people should be able to individually and freely decide. 
Genomic Data Sharing and Protection

Finally, many contributors had a dual attitude towards genomic data sharing. On the one hand, many people were willing to share their data, especially for medical, research, and forensic purposes. Some contributors argued that a central database would be most efficient to store the collected data and referred to several institutions to secure and manage this database, including hospitals, specialised organisations, and the government. On the other hand, many people pointed out that sharing genomic data holds inherently the risk of abuse and harm. The information could end up with "the wrong people," such as insurance companies, employers, or commercial companies, who could take unjustified advantage of it or use it against them. Many contributors expressed a sense of uncertainty about the potential current and future uses of shared data too. They worried about the non-traceability of these data, the actual compared to the announced usage, unknown future research on their data, and safe storage.

DNA analysis and genetic engineering have enormous possibilities. But it means that these possibilities can also be used negatively. Just as nuclear energy has been misused to produce weapons, genetic engineering could have consequences we cannot foresee yet. It is important to consider consequences we can predict as well as those we cannot (Thread no. 1188).

Therefore, contributors referred to various preventive measures and different ways to protect data that could support genomic information usage while avoiding abuses and their resulting harms as much as possible. They frequently emphasised privacy as a precondition for genomic data sharing to guarantee that they will not experience any disadvantage or discrimination because of data sharing. Moreover, contributors endorsed the values of transparency and control. They wanted to know who can access and use their data, for which purposes and where they are stored. Procedures for sharing and usage should be controllable and verifiable, either by themselves or by external institutions.

There should be a database with people's data. This database is not online but stored on a special service that only doctors can access in case of emergency, and with the injured person consent (...). The database is protected by a special force that prevents hacking. These are all precautions to avoid data misuses (Thread no. 357).

Contributors often suggested establishing or optimising the legal framework concerning genomic data sharing to realise its benefits while avoiding its risks and potential abuses.
Recommendations on Using Genomic Information

Many contributors had a positive attitude towards and supported the knowledge, use, and sharing of genomic information to good advantage in several contexts. Nevertheless, they were concerned that genomic information could be used against them. Hence, they expected from specialised institutions and public authorities to actively minimise the risks and abuses they feared. Throughout the 5 abovementioned themes, contributors suggested various strategies to realise this consideration:

- Promoting a non-reductionist perspective: despite the impact of DNA on the identity, the influence of education, environment, and social context should be taken into account.

- Avoiding a genomic imperative: even though genomic information may contribute to individual and societal benefit, people should not be obliged to know or use this information. People have the right to autonomously decide on the information they receive and the actions they perform. The right not to know and the right to an open future should be preserved.

- Avoiding genomic discrimination: there is a societal responsibility not to discriminate people based on their genetic makeup, even when they are informed about or do not behave in accordance with their genomic information.

- Respecting privacy: since genomic information is ultimately personal, its societal usage should occur responsibly and with respect for a person's privacy and integrity. Anonymous data sharing and use are essential to avoid genomic discrimination;

- Ensuring traceability of and control over shared data: when people share their genomic data, they want to know where these are stored, who can access these, and for which purposes these are used. People want to have some control over these issues by consenting to specific data sharing and usage. Additionally, specialised institutions or governmental authorities should control whether genomic information is used responsibly or not.

- Protecting people against abuses: many contributors emphasised the need to develop national or international legal frameworks that inhibit potential misuses of shared genomic information.

\section{Discussion}

This article describes the results of the online Belgian DNA debate in which citizens were asked about their perspective on the societal use of genomic information, its associated ELSI, and underlying norms and values. In the contributions to the deliberative platform, 5 main themes were identified.

\section{DNA and Identity}

Contributors considered DNA as highly significant for someone's identity. The general population has previously described DNA as someone's most personal informa- 
tion and even as an individual "instruction manual" [5, $20,21]$. Genomic information has also been considered categorically different from other types of information because of its uses outside of health care and its familial implications, which may require specific management $[13,20]$. These general ideas on genetics and identity reflect findings of more specific psychosocial research, for example, by McConkie-Rosell and colleagues, which thoroughly described the impact of a genetic carrier status on a person's self-concept or wished-for parental role $[22,23]$. Likewise, d'Agincourt-Canning described how positive results from BRCA 1/2 testing affect the physical, familial-relational, and social self-concept of concerned people [24]. Negative and pre-symptomatic test results may carry an impact as well and bring about feelings of, respectively, survivor guilt towards affected family members or being in a liminal position of neither being ill nor perfectly healthy [24]. In non-clinical contexts, genetic ancestry testing, for instance, may prompt people to understand human traits and racial differences as genetically determined, although people may also integrate results only selectively into their identity $[25,26]$.

Despite these ideas on the impact of genetics and genomics, contributors simultaneously thought that people should not be judged solely on their genetic makeup. This non-deterministic perspective on genetics that acknowledges the influence of lifestyle, environment, and context has been shown before $[21,27,28]$. Citizens have warned against other possible consequences of genomic medicine, such as a reductionist perspective on health, eugenics, and medicalisation [14].

\section{Genomic Information and Its Impact on Behaviour}

Many contributors were interested in at least some genomic information since it could enable valuable preventive actions and lifestyle changes. Equally, participants from other studies reported a selective interest in genomic information: they mainly considered it useful when associated with conditions that allow treatment, prevention, or reproductive interventions $[1,21]$. Besides, several recent studies indicated the general public's interest and high expectations towards the personal use of genomics $[4,12]$, which confirms that in general, the public perspective on genomics has become more optimistic over time $[4,13,22]$.

Despite this interest in genomic information and the behavioural changes it may enable, contributors thought that people should be allowed a (selective) genomic ignorance that facilitates a psychological carelessness and an open future. The general public has frequently referred to psychological distress as a significant risk of receiving genomic information $[5,14,21]$. However, research has indicated that over the long run, distress resulting from positive genomic risk information usually dissipates, for example, in an oncological context $[27,28]$.

\section{Genomic Information and Its Repercussion on Responsibility}

Several contributors mentioned how genomic information could engender a responsibility to act accordingly. However, they noted that people will not always be able or willing to realise this responsibility and may behave in opposition with or beyond their genetic predispositions.

In the light of the tension between, on the one hand, behavioural changes and responsibility, and, on the other hand, freedom and an open future, it may be critical to informing people about the limitations of genomics [5, 29]. Genetic variants may be hard to interpret, the predictive value of these variants may be limited, and preventive options may not always be available. These insights could avoid disappointments about the practical utility of genomic information, as well as a genomic determinism and imperative responsibility $[5,29,30]$.

Furthermore, various contributors believed that society has the responsibility to facilitate the evolution of genomic knowledge and the use of genomic data without allowing genetic discrimination. This wish for a world where genomics advances people's health without discrimination on genomic grounds has been highlighted in previous studies as well, in which people warned for the risks of social injustice [14, 31]. Moreover, citizens are concerned about a society that would become less tolerant of disabled people [1]. Therefore, policymakers should take a long-term perspective on genomics and avoid actions which might result in a stratified society [13].

\section{The Common Good}

Almost all contributors thought that as a general rule, people should be free to decide on the knowledge of their genomic information and its usage. This statement conforms with 3 conclusions from previous studies: the identification of decisions concerning genetic testing and screening as intensely personal decisions; the desire of most citizens to safeguard individual freedom of choice in genomics; and the emphasis on informed consent in all aspects of genomics $[1,14,29,32]$.

Some contributors, nevertheless, argued that in particular situations, the common good could overrule the individual choices or benefits. The idea of contributing 
to the common good, frequently described as the progress of medical science or population health, has already stimulated people to contribute to biobanks or projects, such as the 100,000 Genomes Project [13, 33, 34]. People realised that participation might not be personally beneficial, but they wanted to contribute to future generations, the community, and a long-term common cause as an act of solidarity [34]. This general willingness to contribute should, nevertheless, not lead policymakers to ignore, for instance, ethnic minority groups that might be less willing to donate their DNA because of real fears of legal or political authorities and discrimination [4].

\section{Genomic Data Sharing and Protection}

Almost all contributors were willing to share their genomic data for medical and research purposes. Other studies reported that many people feel disposed to contribute to science and agree that genomic data can be used for clinical care and research simultaneously [13,21]. Citizens generally realise that genomic information is relevant for others too, and hence, consider this information rather collective than merely individualistic [5, 13]. Thereby, sharing genomic data has been considered a combination of altruism and reciprocity: people want to contribute to research but expect to share in its potential benefits too [13].

However, people's willingness to share may be strongly affected by their trust in the individuals and organisations that collect, store, and use the data. Similar to our study, other studies show that citizens are willing to share their data in particular with medical doctors, hospitals, and non-profit researchers $[1,9,20,34]$. Contrarily, people express a notably smaller willingness to share with for-profit researchers and companies $[9,20]$.

Both participants of our study and other citizen forums were aware of the risks of data sharing. They were frequently concerned about data abuses, for instance, by employers and insurance companies [6, 21, 29, 34]. According to a Belgian survey, one-quarter of the general population worried that the genetic test results could "fall into the wrong hands" [1]. This expression has been cited many times on the deliberative platform of our study. To address this concern, many contributors identified privacy protection, transparency, and control as fundamental conditions that must be met, which is consistent with values cited in previous citizens' consultations [13, 14, 29]. Genomic databases and clinical and research programs should be governed in a participantcentred and transparent way and should, for example, allow for the removal of data or require specific permission for the reuse of data $[4,6]$. Finally, contributors called for a legal framework to protect their shared genomic data. This call for regulatory supervision and robust governance has been expressed before $[1,13,21]$. Moreover, innovative legal frameworks should be developed that enable responsible and secure data sharing across countries $[2,4]$.

\section{A Soft Version of the Precautionary Approach}

As noted in previous citizens' consultations, most contributors expressed a dual attitude in genomics since they realised that genomic data could be used both for better or worse $[10,12]$. Hence, they made a trade-off between the valuable benefits of genomic information usage and its potential risks and harms and suggested various protections against these risks. Contributors' dual attitude may be partly explained by the 2 -fold nature of the subquestions on the online deliberative platform, for instance, "What motivates me to share my DNA data, or what stops me from doing so? Why?" Notwithstanding this, contributors' awareness of both benefits and risks and harms of genomic information usage, and their resulting need for protective measures align with the elements of the precautionary approach. The precautionary approach stipulates that anticipatory actions should be taken when actions may - but not necessarily will - lead to harm, to avoid or reduce this harm $[35,36]$. Various ideas from contributors further reflected central points of the precautionary approach. Firstly, statements like "It is important to consider the consequences we can predict as well as those we cannot" (cf. supra, Thread no. 1188) reflect the uncertainty and lack of scientific proof regarding potential risks and harms. Secondly, contributors assigned the responsibility for preventive measures against (uncertain) risks to institutions seeking to establish the usage of genomic information, for instance, the government.

According to the strong version of the precautionary principle, one should refrain from actions as long as there is no scientific proof that these actions will not cause harm, to avoid these harms [37]. Applied to genomic information, this would imply a moratorium on several of its usages [38]. However, contributors did not call for a radical implementation stop of genomic information usage but urged that measures should be taken to avoid or minimise risks of new technologies when these may result in harm. Hence, they expressed a soft and moderate version of the precautionary approach, which does not try to avoid risks by all means (since this also eliminates the 
benefits of genomic information), but where prudence and the weighing of different values (e.g., privacy, transparency, scientific progress, and clinical benefit) should result in protective measures that are proportional to the potential risks and harms [37-39].

\section{Future Research}

The ELSI approach is suitable to engage a large number of citizens on a sensitive and interdisciplinary topic such as the societal use of genomic information. Because its ethical, legal, and societal (including economics) issues are heavily linked, addressing them all at once is mutually enhancing, more efficient, and likely to capture the complex reality of genomics. Several studies tackled the ELSI of genomics from a public perspective as well. Some, such as the Sienna project, pursued a broad perspective and considered various technological issues such as human genomics, human enhancement, and artificial intelligence by both quantitative and qualitative approaches [12]. Others, such as the Genomics England project, focused on the impact of genomics on specific concepts such as "social contract" [13]. The deliberative platform we organised specifically aimed for public views concerning the societal usage of genomic information and this in a well-informed and deliberative, yet bottom-up, way that was not directed by predefined concepts.

Despite its interdisciplinary perspective on genomics, the ELSI approach may not grasp the overall picture. Other approaches to technology governance and policy could further develop our results. A responsible research and innovation approach (in which socio-economic goals are considered through partnerships with industry) or a constructive technology assessment (in which technological development and implementation processes are considered from the perspective of social actors, such as consumers) may be valuable [12]. Also approaches drawing from feminist studies of technology, critical theory, and critical policy studies, for instance, could take political aspects more explicitly into account.

\section{Conclusion}

This article describes Belgian citizens' values and norms concerning the societal use of genomic information and its associated ELSI. While reflecting on issues about identity, behaviour, responsibility, the common good, and data sharing, many contributors supported a soft precautionary approach in which the benefits of genomic information can only be realised when propor- tional protective measures avert potential risks and harms. In our opinion, the increased implementation of genomic information in several societal domains should continuously be supported by citizens' perspectives. Further initiatives should be taken to inform, involve, and engage them.

\section{Acknowledgements}

We acknowledge Tree Company and Levuur for creating the deliberative platform and their expert advice on recruitment and information dissemination. This publication arises from the Innovative Partnership for Action against Cancer Joint Action, which has received funding from the European Union through the Consumers, Health, Agriculture, and Food Executive Agency of the European Commission, in the framework of the Health Programme 2014-2020. The content of this publication represents the views of the authors only and is their sole responsibility; it cannot be considered to reflect the views of the European Commission and/or the Consumers, Health, Agriculture, and Food Executive Agency or any other body of the European Union. The European Commission and the Agency do not accept any responsibility for use that may be made of the information it contains. The authors are not responsible for any further and future use of the publication by third parties and third-party translations.

\section{Statement of Ethics}

No ethics committee was consulted since the research of publicly accessible conversations gathered in a publicly accessible venue is not considered as human subjects research [40]. When visiting the dedicated Website (dnadebat.be/debatadn.be), citizens could voluntarily contribute to the debate through its deliberative platform. The design of the Website and its operational rules informed participants that all contributions are published on the platform, after being moderated. Since citizens intentionally contributed to a public and viewable debate, no additional and explicit consent was obtained. Nevertheless, attention was paid to protect the participants' privacy and integrity. All contributors were anonymous, choosing their alias. Moreover, each contribution was moderated to eliminate offensive language and trolling.

\section{Conflict of Interest Statement}

The authors have no conflicts of interest to declare.

\section{Funding Sources}

The DNA debate project was funded by Sciensano and the EU Innovative Partnership for Action Against Cancer (iPAAC) Joint Action which is funded by the European Union's Health Programme (2014-2020). 


\section{Author Contributions}

C.M. and W.V.H. developed the concept and design of the Belgian DNA debate. They created the content of the Website, recruited participants, and moderated the deliberative platform. The contributions to the deliberative platform were analysed themati- cally by C.M., M.S., and W.V.H. They jointly discussed and revised theme names, definitions, and structures until consensus was reached. M.S. was a major contributor in writing the manuscript, while C.M. and W.V.H. fundamentally reviewed draft manuscripts and contributed to the manuscript's final structure. All authors have read and approved the final manuscript.

\section{References}

1 Chokoshvili D, Belmans C, Poncelet R, Sanders S, Vaes D, Vears D, et al. Public views on genetics and genetic testing: a survey of the general public in Belgium. Genet Test Mol Biomarkers. 2017 Mar;21(3):195201.

2 Stark Z, Dolman L, Manolio TA, Ozenberger B, Hill SL, Caulfied MJ, et al. Integrating genomics into healthcare: a global responsibility. Am J Hum Genet. 2019 Jan;104(1):1320.

3 European "1+ Million Genomes" Initiative [Internet]. [cited 2020 Oct 7]. Available from: https: //ec.europa.eu/digital-single-market/ en/european-1-million-genomes-initiative.

4 Middleton A, Milne R, Thorogood A, Kleiderman E, Niemiec E, Prainsack B, et al. Attitudes of publics who are unwilling to donate DNA data for research. Eur J Med Genet. 2019.

5 Ballard LM, Horton RH, Fenwick A, Lucassen AM. Genome sequencing in healthcare: understanding the UK general public's views and implications for clinical practice. Eur J Hum Genet. 2020 Feb;28(2):155-64.

6 Briscoe F, Ajunwa I, Gaddis A, McCormick J. Evolving public views on the value of one's DNA and expectations for genomic database governance: results from a national survey. PLOS One. 2020 Mar;15(3):e0229044.

7 Middleton A, Milne R, Howard H, Niemiec E, Robarts L, Critchley C, et al. Members of the public in the USA, UK, Canada and Australia expressing genetic exceptionalism say they are more willing to donate genomic data. Eur J Hum Genet. 2020 Apr;28(4):424-34.

8 van El CG, Cornel MC, Borry P, Hastings RJ, Fellmann F, Hodgson SV, et al. Whole-genome sequencing in health care: recommendations of the European society of human genetics. Eur J Hum Genet. 2013 Jun;21(6): $580-4$.

9 Milne R, Morley KI, Howard H, Niemiec E, Nicol D, Critchley C, et al. Trust in genomic data sharing among members of the general public in the UK, USA, Canada and Australia. Hum Genet. 2019 Dec;138(11-12):123746.

10 Van Valckenborgh E, Hébrant A, Antoniou A, Van Hoof W, Van Bussel J, Pauwels P, et al. Roadbook for the implementation of next-generation sequencing in clinical practice in oncology and hemato-oncology in Belgium. Arch Public Health. 2018 Sep; 76(49):49.
11 Dryzek JS, Nicol D, Niemeyer S, Pemberton S, Curato N, Bächtiger A, et al. Global citizen deliberation on genome editing. Science. 2020 Sep;369(6510):1435-7.

12 Soulier A, Niemiec E, Carmen H. Ethical analysis of human genetics and genomics. Public deliverable report from the SIENNA project; 2019. Available from: https:// ec.europa.eu/research/participants/documents/downloadPublic?documentIds $=0801$ 66e5c70bb81d\&appId=PPGMS.

13 IPsos MORI, Bukowski G, Castell S, Wayne E, Yetman S. A public dialogue on genomic medicine: time for a new social contract? London; 2019. Available from: https://www. ipsos.com/sites/default/files/ct/publication/ documents/2019-04/public-dialogue-on-genomic-medicine-full-report.pdf.

14 Comité consultatif national d'éthique. Rapport de synthèse du Comité consultatif national d'éthique: opinions du comité citoyen: EDP Sciences; 2018. Available from: https:// etatsgenerauxdelabioethique.fr/media/default/0001/01/cd55c2a6be2d25e9646bc0d9f28ca25e412ee3d4.pdf.

15 Mayeur C, Van Hoof W. My DNA, everybody's business? Qualitative analysis of the Belgian citizen forum on the use of genomic information. Brussels, Belgium: Sciensano; 2020. Available from: www.e-cancer.be/nl/ final-report-my-dna-everybodys-businessqualitative-analysis-belgian-citizen-forumuse-genomic.

16 Parkinson J, Mansbridge J. Deliberative systems: deliberative democracy at the large scale: Cambridge University Press; 2012.

17 Felicetti A. Citizen forums in the deliberative system. Democr Theory. 2014 Dec;1(2):95103.

18 Monnoyer-Smith L, Wojcik S. Technology and the quality of public deliberation: a comparison between on and offline participation. Int J Electron Gov. 2012 Jan;5(1):24-49.

19 Braun V, Clarke V. Using thematic analysis in psychology. Qual Res Psychol. 2006;3(3): 77-101.

20 Voigt TH, Holtz V, Niemiec E, Howard HC, Middleton A, Prainsack B. Willingness to donate genomic and other medical data: results from Germany. Eur J Hum Genet. 2020: 1-10.
21 Metcalfe SA, Hickerton C, Savard J, Terrill B, Turbitt E, Gaff C, et al. Australians' views on personal genomic testing: focus group findings from the Genioz study. Eur J Hum Genet. 2018 Aug;26(8):1101-12.

22 McConkie-Rosell A, DeVellis BM. Threat to parental role: a possible mechanism of altered self-concept related to carrier knowledge. J Genet Couns. 2000;9(4):285-302.

23 McConkie-Rosell A, Spiridigliozzi GA, Melvin E, Dawson DV, Lachiewicz AM. Living with genetic risk: effect on adolescent selfconcept. Am J Med Genet C Semin Med Genet. 2008;148C(1):56-69.

24 D'Agincourt-Canning L. A gift or a yoke? Women's and men's responses to genetic risk information from BRCA1 and BRCA2 testing. Clin Genet. 2006;70(6):462-72.

25 Panofsky A, Donovan J. Genetic ancestry testing among white nationalists: from identity repair to citizen science. Soc Stud Sci. 2019;49(5):653-81.

26 Shim JK, Rab Alam S, Aouizerat BE. Knowing something versus feeling different: the effects and non-effects of genetic ancestry on racial identity. New Genet Soc. 2018 Jan; 37(1):44-66.

27 Smith AW, Dougall AL, Posluszny DM, Somers TJ, Rubinstein WS, Baum A. Psychological distress and quality of life associated with genetic testing for breast cancer risk. Psychooncology. 2008;17(8):767-73.

28 Fenton GL, Smit AK, Keogh L, Cust AE. Exploring the emotional and behavioural reactions to receiving personalized melanoma genomic risk information: a qualitative study. Br J Dermatol. 2019;180(6):1390-6.

29 Meiser B, Storey B, Quinn V, Rahman B, Andrews L. Acceptability of, and information needs regarding, next-generation sequencing in people tested for hereditary cancer: a qualitative study. J Genet Couns. 2016;25(2): 218-27.

30 Vears DF, Sénécal K, Clarke AJ, Jackson L, Laberge AM, Lovrecic L, et al. Points to consider for laboratories reporting results from diagnostic genomic sequencing. Eur J Hum Genet. 2018 Jan;26(1):36-43.

31 Raeymaekers P, Teller M, King Baudouin Foundation. Genoomkennis verandert de gezondheidszorg - Burgeradvies zet beleid en stakeholders aan tot veranderagenda. Brussels: King Baudouin Foundation; 2019. 
32 Flatau L, Reitt M, Duttge G, Lenk C, Zoll B, Poser W, et al. Genomic information and a person's right not to know: A closer look at variations in hypothetical informational preferences in a German sample. PLoS One. 2018 Jun;13(6):e0198249.

33 Hobbs A, Starkbaum J, Gottweis U, Wichmann HE, Gottweis $\mathrm{H}$. The privacy-reciprocity connection in biobanking: comparing German with UK strategies. Public Health Genomics. 2012;15(5):272-84.
34 Dheensa S, Lucassen A, Fenwick A. Fostering trust in healthcare: participants' experiences, views, and concerns about the 100,000 genomes project. Eur J Med Genet. 2019 May;62(5):335-41.

35 Jordan A, O’Riordan T. The precautionary principle: a legal and policy history. The precautionary principle: protecting public health, the environment and the future of our children: World Health Organization; 2004.

36 UNESCO, Comest. The Teaching of Environmental Ethics. 2009.
37 ter Meulen RHJ. The ethical basis of the precautionary principle in health care decision making. Toxicol Appl Pharmacol. 2005 Sep; 207(2 Suppl 1):663-7.

38 Clarke S. Future technologies, dystopic futures and the precautionary principle. Ethics Inf Technol. 2005 Sep;7(3):121-6.

39 Resnik DB. The precautionary principle and medical decision making. J Med Philos. 2004 Jun;29(3):281-99.

40 Kantanen H, Manninen J. Hazy boundaries: virtual communities and research ethics. MaC. 2016 Oct;4(4):86-96. 